QUEZADO-DUVAL AM; NASCIMENTO AR; PONTES NC; MOITA AW; ASSUNÇÃO A; GOLYNSKI A; INOUE-NAGATA AK; OLIVEIRA RT; CASTRO YO; MELO BJ. 2014. Desempenho de híbridos de tomate para processamento industrial em pressão de begomovirose e de mancha-bacteriana. Horticultura Brasileira 32: 446-452. DOI - http://dx.doi.org/10.1590/S0102-053620140000400012

\title{
Desempenho de híbridos de tomate para processamento industrial em pressão de begomovirose e de mancha-bacteriana
}

\author{
Alice M Quezado-Duval ${ }^{1}$; Abadia R Nascimento ${ }^{3}$; Nadson C Pontes ${ }^{2}$; Antonio W Moita ${ }^{1}$; Aracelle \\ Assunção $^{1}$; Adelmo Golynski²; Alice K Inoue-Nagata ${ }^{1}$; Raísa T Oliveira²; Yuri O Castro²; Breno J Melo \\ ${ }^{1}$ Embrapa Hortaliças, C. postal 218, 70351-970 Brasília-DF; alice.quezado@embrapa.br (autor para correspondência); aracelle. \\ assunção@colaborador.embrapa.br; alice.nagata@embrapa.br; ${ }^{2}$ IF Goiano campus Morrinhos, C. postal 92, 75650-000 Morrinhos- \\ GO; nadson.pontes@ifgoiano.edu.br; adelmo.golynski@ifgoiano.edu.br; raisaturcato@hotmail.com; yuricastro.agro@hotmail.com; \\ brenojm@hotmail.com; ${ }^{3}$ UFG-EAEA, C. postal 131, 74690-900 Goiânia-GO; abadiadosreis@ufg.br
}

\section{RESUMO}

A mancha-bacteriana e a begomovirose são exemplos de doenças importantes em tomate para processamento industrial no Brasil em que a disponibilização de cultivares com resistência é extremamente desejável. No presente trabalho foram conduzidos três ensaios $(2010$ e 2011) para avaliar híbridos comerciais e experimentais de tomate para processamento industrial em campo, com ocorrência de begomovirose (ensaios 1 e 3 ) e de mancha-bacteriana (ensaios 2 e 3 ). $\mathrm{O}$ delineamento experimental em 2010 foi blocos ao acaso e, em 2011, blocos ao acaso com parcelas subdivididas, cabendo à parcela a inoculação de Xanthomonas perforans e/ou X. gardneri (com e sem) e, à subparcela, os híbridos. A infecção por begomovírus foi natural. A severidade de ambas as doenças foi mensurada por atribuição visual de notas. Foi calculado a estimativa do efeito relativo de tratamento para severidade das doenças quando tomada em uma única avaliação (ensaios 1 e 2) e a Área Abaixo da Curva de Progresso da Mancha-bacteriana (AACPMab) para a severidade estimada em quatro datas (ensaio 3). Avaliou-se ainda a produtividade nos três ensaios. Foram observadas diferenças significativas entre os híbridos em relação à severidade das doenças estudadas (três ensaios) e produtividade (ensaios 2 e 3). Os híbridos BRS Sena, HF1-50 e BQ-210 tiveram melhor comportamento em relação à begomovirose no ensaio 1. Para a mancha-bacteriana (ensaio 2), sete híbridos tiveram estimativa do efeito relativo de tratamento inferiror a 0,50 , porém com muita sobreposição entre os intervalos de confiança. A produtividade variou de 33,7 (BQ 145) a 56,5 t/ha(BRS Sena). No ensaio 3, o híbrido BRS Sena novamente colocou-se entre os materiais com melhor desempenho para begomovirose, enquanto, em conjunto com os híbridos CVR 54, BA 5446 e HMX 7889, apresentou AACPMab significativamente menor que os materiais mais suscetíveis. Em seis híbridos a mancha-bacteriana reduziu significativamente (41,4\% em média) a produtividade, que variou de 95,8 (AP 533) a 138,0 t/ha (BA 5446).

Palavras-chave: Solanum lycopersicum, Tomato severe rugose virus, Xanthomonas perforans, $X$. gardneri, análise não-paramétrica, estatística-teste F.

\section{ABSTRACT}

Field performance of processing tomato hybrids under bacterial spot and begomovirus pressure

Begomoviruses and bacterial spot are examples of important limiting yield factors for the processing tomato crop in Brazil in which the availability of resistant cultivars is strongly welcome. Three field trials were carried out in 2010 and 2011 to evaluate commercial and experimental processing tomato hybrids under begomovirus (trial 1) and bacterial spot (trials 2 and 3 ) pressure. Blocks at random were used in trials 1 and 2 (2010), while trial 3 (2011) was carried out in a split-plot randomized blocks design, where Xanthomonas perforans and/or X. gardneri inoculation (yes or no) was tested in main plots and hybrids, in sub-plots. Begomovirus infection was natural. Both diseases were assessed independently by using visual severity rates. Whenever diseases were assessed in a single evaluation (trials 1 and 2 ), we estimated the treatment relative effect for disease severity; while for multiple evaluations (bacterial spot, trial 3), we calculated the Area Under the Bacterial Spot Progress Curve (AUBSPC). Yield data were also taken. Significant differences were detected for disease severity in the three trials and for yield in trials 2 and 3. Hybrids BRS Sena, HF1-50, and BQ-210 performed better for resistance to begomoviruses in trial 1. For bacterial spot (trial 2), seven hybrids had estimated relative effet lower than 0.50 , but with intense confident interval overlapping among hybrids. Yields varied from 33.7 (BQ 145 ) to $56.5 \mathrm{t} / \mathrm{ha}$ (BRS Sena). In trial 3, BRS Sena performed again among the most resistant to begomovirus, and along with CVR 54, BA 5446, and HMX 7889 showed an AUBSPC significantly lower than those of the most susceptible hybrids. In six hybrids the bacterial spot significantly reduced yield (41.4\% in average), which varied from 95.8 (AP 533) to 138.0 t/ha (BA 5446).

Keywords: Solanum lycopersicum, Xanthomonas perforans, Xanthomonas gardneri, begomovirus, Tomato severe rugose virus, nonparametric analysis, F-statistics.

(Recebido para publicação em 31 de março de 2014; aceito em 23 de setembro de 2014) (Received on March 31, 2014; accepted on September 23, 2014)

A tomaticultura brasileira para processamento industrial, que atualmente concentra-se em Goiás $(86 \%)$,
São Paulo (12,7\%) e Minas Gerais $(1,3 \%)$, tem apresentado aumento de qualidade, produção e produtividade
(Vilela et al., 2012). Em Goiás, o município de Morrinhos merece destaque na produção de tomate para indústria, tanto 
em área plantada como em produção, além de fazer parte da microrregião da Meia Ponte, que apresenta os maiores valores de produção, área plantada e produtividade do estado (Alves et al., 2006, Camargo et al., 2006a, b). Boa parte dessa produção está destinada às indústrias localizadas no próprio município, fato que aumenta ainda mais a importância da cultura para a economia da região (Costa \& Santos, 2010).

Historicamente, um fator que contribuiu de forma expressiva para o aumento da produtividade no segmento agrícola tomate para processamento industrial foi o uso de híbridos de alto potencial produtivo, que hoje dominam o mercado do segmento (Melo \& Vilela, 2004; Camargo et al., 2006b). A introdução de novos híbridos ficou a cargo de empresas transnacionais de sementes, que não realizam o melhoramento no Brasil, limitando-se a avaliar aqui materiais desenvolvidos em outros países (Melo \& Vilela, 2005). Entre os híbridos mais plantados no Brasil, destacam-se Heinz 9553, Heinz 9992 (Heinz Seeds), AP 533, AP 529 (Seminis Vegetable Seeds) e U 2006 (Nunhems Brasil-Bayer Crop Science) (Boiteux et al., 2012).

Em função das distintas condições edafoclimáticas de cultivo do tomate para processamento industrial no Brasil, é de interesse a avaliação do desempenho de novos híbridos ofertados pelo mercado de sementes em comparação com os tradicionais. Além disso, o desenvolvimento de híbridos nacionais pode vir a propiciar a disponibilização de materiais mais adaptados, que atendam melhor às demandas dos produtores e empresas processadoras que atuam no país (Aragão et al., 2004).

Entre as principais demandas dos produtores locais quanto aos materiais para plantio, tem destaque a busca por materiais mais resistentes a doenças. A ocorrência de epidemias cada vez mais severas de mancha-bacteriana e begomovirose, aliada à dificuldade de controle dessas duas doenças, têm feito com que elas sejam consideradas os principais problemas fitossanitários da cultura do tomateiro para processamento (Quezado-Duval et al., 2004; Giordano et al., 2005; Villas-Bôas et al., 2007;
Fernandes et al., 2008).

Quatro espécies de Xanthomonas podem causar a mancha-bacteriana do tomateiro: $X$. euvesicatoria, $X$. vesicatoria, $X$. gardneri e $X$. perforans (Jones et al., 2004), todas presentes no Brasil (Quezado-Duval et al., 2005). Quatro raças, denominadas T1, T2, T3 e T4, foram identificadas até o presente de acordo com a reação de resistência do tipo hipersensibilidade ou de suscetibilidade em hospedeiras diferenciais. As genoespécies têm-se apresentado nas seguintes raças: T1 (X. euvesicatoria), T2 (X. vesicatoria e $X$. gardneri), T3 e T4 (X. perforans) (Obradovic et al., 2004; Quezado-Duval et al., 2004; Jones et al., 2005).

Fontes de resistência à mancha-bacteriana tanto quantitativas, quanto baseadas na reação de hipersensibilidade têm sido encontradas em tomateiro (Stall et al., 2009). Resistência para T1 foi encontrada em Hawaii 7998 (Wang et al., 1994) e, para T3, em Hawaii 7981, PI 128216 e PI 126932 (Scott et al., 1995). Já o genótipo PI 114490 , por exemplo, tem mostrado níveis quantitativos de resistência, com maior amplitude em relação às raças (Yang et al., 2005; Robbins et al., 2009; Stall et al., 2009).

A begomovirose, também conhecida como geminivirose ou mosaico dourado do tomateiro, tem como agente causal pelo menos dezessete espécies do gênero Begomovirus no Brasil (Castillo-Urquiza et al., 2008; Albuquerque et al., 2010), todos transmitidos por moscas-brancas (Bemisia tabaci). Há predominância de duas espécies na atualidade, Tomato severe rugose virus (ToSRV) no centro-sul e Tomato mottle leaf curl virus (TMoLCV) no nordeste brasileiro (Fernandes et al., 2008). Os fortes sintomas de clorose internerval, encarquilhamento e nanismo podem inviabilizar o cultivo em regiões de alta infestação de moscas-brancas virulíferas. Há disponibilidade de genes que conferem resistência ao tomateiro contra begomovírus e a oferta de híbridos com resistência moderada é observada em tomateiro de crescimento indeterminado. Para o segmento de crescimento determinado, são poucos os híbridos que apresentam a características de resistência, destacando-se atualmente o TY2006 (Seminis Vegetable Seeds), que se destina ao segmento para mesa.

Considerando, portanto, a importância da mancha-bacteriana e da begomovirose para a cadeia produtiva do tomate para processamento industrial, o presente trabalho teve como objetivo avaliar a severidade de ambas as doenças nos principais híbridos disponíveis de tomate para processamento no mercado brasileiro, além de avaliar também alguns híbridos experimentais, bem como o desempenho produtivo destes materiais frente à ocorrência dessas doenças.

\section{MATERIAL E MÉTODOS}

Os ensaios foram conduzidos na área experimental do Instituto Federal Goiano, Campus Morrinhos-GO (1749'29'S, 49¹2'6”O, altitude $892 \mathrm{~m}$ ), em um Latossolo Vermelho distrófico típico, cujas características físico-químicas foram: $\mathrm{pH}-\mathrm{CaCl}_{2}(6,0)$, P-Mehlich (27,3 mg/dm $\left.{ }^{3}\right), \mathrm{K}(70,0 \mathrm{mg} /$ $\left.\mathrm{dm}^{3}\right), \mathrm{Ca}\left(3,4 \mathrm{cmol}_{\mathrm{c}} / \mathrm{dm}^{3}\right), \mathrm{B}(0,17 \mathrm{mg} /$ $\left.\mathrm{dm}^{3}\right), \operatorname{Mg}\left(0,9 \mathrm{cmol}_{\mathrm{c}} / \mathrm{dm}^{3}\right), \operatorname{Al}\left(0,0 \mathrm{cmol}_{\mathrm{c}} /\right.$ $\left.\mathrm{dm}^{3}\right), \mathrm{H}+\mathrm{Al}\left(2,1 \mathrm{cmol}_{\mathrm{c}} / \mathrm{dm}^{3}\right)$, matéria orgânica $\left(18,5 \mathrm{~g} / \mathrm{dm}^{3}\right)$, areia $(455 \mathrm{~g} / \mathrm{kg})$, limo (110 g/kg) e argila (435 g/kg). A recomendação de adubação foi efetuada com base nos resultados da análise do solo visando uma produtividade de 100 t/ha, de acordo com a $5^{\mathrm{a}}$. Aproximação para o Estado de Goiás (Comissão de fertilidade de solos de Goiás, 1988).

Foram realizados três ensaios: 1) março a julho de 2010 ; 2) junho a outubro de 2010 e 3) junho a outubro de 2011. Foram avaliados híbridos comerciais de tomate para processamento industrial disponíveis no mercado brasileiro [AP 529 e AP 533 (Seminis do Brasil), BRS Sena (Eagle Flores, Frutas \& Hortaliças/Embrapa), Heinz 5503, Heinz 9553 e Heinz 9992 (Eagle Flores, Frutas \& Hortaliças), HMX 7889 (Harris Moran/Agristar do Brasil), N-901, U2006 e U232 (Nunhems Brasil-Bayer Crop Science) e UG 8169 (United Genetics/Agristar do Brasil)] e alguns híbridos experimentais: [BA 5446, BQ 145, BQ 210, BQ 211 e E 8755 (Eagle Flores, Frutas \& Hortaliças), CVR 54 
(CVR Plant Breeding Ltda), HF1-50 (Embrapa) e SVR 0453 (Seminis do Brasil)]. No ensaio 3, o número de híbridos avaliados foi reduzido, dando-se foco aos materiais mais plantados e adicionando-se dois outros materiais experimentais (BA 5446 e E 8755), de acordo com a demanda das empresas de sementes que atuam no país.

O primeiro e o segundo ensaios foram realizados em blocos ao acaso. $\mathrm{O}$ terceiro ensaio foi realizado em blocos casualizados com parcelas subdivididas, avaliando-se nas parcelas o tratamento inoculação (com e sem) e, nas subparcelas, os híbridos. Em todos os ensaios foram utilizadas três repetições e a parcela útil foi composta de duas linhas com 14 plantas cada, sendo o híbrido Heinz 9992 utilizado para formar as bordaduras. As plantas foram dispostas em linhas duplas com espaçamento interno de $70 \mathrm{~cm}$ entre linhas, $1,10 \mathrm{~m}$ entre as duplas de linhas e $37 \mathrm{~cm}$ entre plantas.

As mudas foram produzidas em viveiro comercial localizado em Morrinhos-GO. A semeadura foi efetuada em bandejas de poliestireno expandido de 450 células contendo substrato comercial de fibra de coco (Amafibra ${ }^{\circledR}$ ). O plantio ocorreu 25 dias após a semeadura, quando as mudas apresentavam de duas a três folhas verdadeiras. No campo, as plantas foram irrigadas diariamente após o plantio até o completo enraizamento, que ocorreu em cerca de uma semana. Após esse período, o turno de rega foi de duas irrigações por semana, com lâmina de irrigação de 10 mm até a quarta semana após o plantio e $15 \mathrm{~mm}$ da sexta à 14ㄹ semana (aproximadamente 100 dias), quando a irrigação foi suspensa para acelerar a maturação dos frutos, sendo este procedimento comum nos cultivos comerciais. A área foi irrigada por aspersão utilizando-se um sistema de pivô central. O controle de moscas-brancas foi realizado com a aplicação de inseticidas químicos (Villas Bôas \& Castelo Branco, 2009).

Nos ensaios 1 e 3, os híbridos foram avaliados quanto à severidade da begomovirose, que ocorreu por infecção natural, face à presença de populações virulíferas de mosca-branca (Bemisia tabaci biótipo B) e cultivos de tomate para processamento em áreas próximas.
A severidade nos híbridos foi avaliada entre os 70 e 90 dias após o plantio, quando a doença já se encontrava uniformemente distribuída no campo, uma vez que as bordaduras manifestavam igual sintomatologia por toda a área do ensaio. Para a avaliação da begomovirose foram atribuídas notas às parcelas visualmente por um avaliador experiente, onde: $1=$ ausência de sintomas nas plantas, $2=$ sintomas moderados (clorose internerval e leve enrugamento dos folíolos) e $3=$ sintomas severos (enrugamento severo, clorose internerval e redução severa do crescimento) (Giordano et al., 2005). Cinco amostras de plantas com sintomas de infecção por begomovírus foram coletadas ao acaso no ensaio. A confirmação da infecção por begomovírus foi feita por amplificação do DNA viral por reação de polimerase em cadeia com os iniciadores universais para begomovírus em amostras individuais (Rojas et al., 1993). Realizou-se a análise do perfil de amplificação por círculo rolante e digestão com a enzima de restrição MspI (New England Biolabs) (Barreto et al., 2013) e do sequenciamento direto de produto de amplificação por círculo rolante e clonagem de alguns dos begomovírus, para a identificação da espécie do vírus presente na região.

No segundo e terceiro ensaios buscou-se avaliar a resistência dos híbridos à mancha-bacteriana. No segundo ensaio não foi avaliada a infecção por begomovírus, em função da menor incidência da doença observada nas bordaduras. Já no terceiro, as notas relativas à severidade da begomovirose foram atribuídas apenas para as parcelas não inoculadas, uma vez que os sintomas de mancha-bacteriana (necrose foliar e amarelecimento) se confundiam com os da begomovirose (mosaico e encarquilhamento). As inoculações da(s) bactéria(s) foram feitas pulverizando, com o uso de um equipamento de $\mathrm{CO}_{2}$ manual, uma suspensão bacteriana ajustada para aproximadamente $5 \times 10^{7}$ ufc/mL, pela diluição 1:10 de uma suspensão originalmente ajustada para O.D. ${ }_{600 \mathrm{~nm}}=0,3$ em espectrofotômetro. As inoculações deram-se da seguinte forma: Ensaio 2, um isolado de $X$. gardneri, 37 dias após o plantio das mudas (DAP) no campo, e, Ensaio 3, um isolado de $X$. perforans, 14 DAP e um de $X$. gardneri, 30 DAP. A escolha da espécie deu-se em função da época de inoculação, dada a influência distinta da temperatura na patogenicidade causada por cada uma dessas espécies (Araújo et al., 2011).

Para a avaliação da severidade da mancha-bacteriana atribuiu-se notas para a parcela inteira, com base em uma escala visual em níveis progressivos de severidade variando de 1 a 10 (QuezadoDuval et al., 2011). Essas avaliações foram feitas por três avaliadores independentes e ocorreram 89 dias após a inoculação no ensaio 2; e, 50, 63, 70 e 80 dias após a última inoculação, no ensaio 3. Para este ensaio, os dados de severidade nas quatro avaliações foram utilizados para calcular a Área Abaixo da Curva de Progresso da Mancha-bacteriana (AACPMab).

Decorridos 120 dias do plantio, realizou-se a colheita de todas as plantas da linha central da parcela para a estimativa da produtividade, expressa em toneladas por hectare ( $\mathrm{t} / \mathrm{ha})$. Para tanto, a produção total da parcela foi dividida pelo número de plantas que a compunham e o valor obtido multiplicado pela densidade de 30.030 plantas, calculada em função do espaçamento utilizado.

Para as análises estatísticas as notas de severidade foram transformadas em escores e em seguida utilizou-se o procedimento proc mixed com a opção anova, para a correta obtenção da estimativa dos efeitos relativos de tratamentos e a correta estatística-teste F [ATS (Anova Type Statistics), Brunner et al., 2002; Brunner \& Puri, 2001, apud Shah \& Madden, 2004]. A ATS testa a hipótese nula sobre os efeitos relativos dos tratamentos (ER) que é uma generalização da média dos tratamentos estimado por meio da fórmula:

$$
\hat{p}_{i}=\frac{1}{N}\left(\bar{R}_{i}-0,5\right)
$$

onde $\mathrm{N}$ é o número total de observações e $\mathrm{R}_{\mathrm{i}}$, a média dos escores (rank) dos dados para o i-ésimo tratamento.

Os erros-padrão e intervalos de confiança para os efeitos relativos de tratamento foram calculados utilizando-se as macros SAS desenvolvidas por Brunner et al. (2002). Além disso, calculou-se a mediana das notas de severidade das 
doenças, parâmetro que fornece um resumo do valor central dessas variáveis para cada tratamento (Shah \& Madden, 2004) (SAS, v.9.2).

Para produtividades e AACPMab, por serem variáveis contínuas, realizou-se a Anova, assim que confirmados os pressupostos de normalidade do resíduo (Shapiro-Wilk) e homogeneidade de variâncias (Bartlett). Nos casos de efeito significativo $(\mathrm{p} \leq 0,05)$ dos fatores avaliados, as médias foram comparadas pelo teste de Tukey. Coeficientes de correlação de Spearman entre doença e produtividade foram calculados para todos os ensaios (SAS, v.9.2).

\section{RESULTADOS E DISCUSSÃO}

Inicialmente, o begomovírus presente na área experimental foi identificado. A análise genômica dos vírus mostrou que todas as amostras apresentaram perfis de restrição semelhantes. O sequenciamento utilizando o iniciador pARc496 (Rojas et al., 1993) confirmou a infecção por um isolado de ToSRV nas parcelas.

No ensaio 1, foram detectadas diferenças significativas entre os híbridos para begomovirose $(p=0,0002)$, mas não para a produtividade $(\mathrm{p}=0,34)$. Para a begomovirose, os híbridos que apresentaram um ER inferior a 0,50, correspondendo aos menores valores da mediana (severidade de doença), foram BRS Sena, HF1-50 e BQ-210. Observando-se o intervalo de confiança do ER, verifica-se que BRS Sena (ER= 0,03 ) foi o único que não teve sobreposição com os intervalos dos demais híbridos (Tabela 1). Já BQ-210 e HF150 (ambos com $\mathrm{ER}=0,19)$ diferiram apenas do grupo de maior ER $(=0,66)$, representado por AP529, AP533, BQ145, HMX 7889, SVR0453, U2006 e U232 (Tabela 1) sem, no entanto, diferir de BQ-211, Heinz 5503, Heinz 9553, Heinz 9992 e UG 8169. Este grupo de híbridos apresentou maior amplitude no intervalo de confiança (Tabela 1). A correlação de Spearman entre as notas de begomovirose e a produtividade foi negativa $(\mathrm{r}=-0,12)$, mas não significativa $(p=0,436)$. Apesar de ser potencialmente prejudicial, em infecções tardias a begomovirose pode não afetar a produtividade, o que pode ter ocorrido durante esse ensaio.

No ensaio 2 foram detectadas diferenças significativas entre os híbridos tanto para a severidade da mancha-bacteriana $(p=0,0082)$, como para produtividade $(\mathrm{p}=0,0100)$. Para reação a esta doença, sete híbridos apresentaram $\hat{p}_{i}$ inferior a 0,50 , correspondendo aos menores valores da mediana, ou seja, à menor severidade de doença (Tabela 2). Porém, como houve grande amplitude dos intervalos de confiança para severidade de doença nos híbridos em geral, a maior de 0,14 a 0,90 (AP 533) e, a menor, de 0,05 a 0,21 (HF1-50) (Tabela 2), observou-se grande sobreposição desses intervalos. Desse modo, só puderam ser distinguidos o híbrido HF1-50 dos híbridos AP 529, BQ-145, BQ-210, Heinz 5503, BRS Sena, SVR 0453, U 2006 e UG 8169, por não ter sido observado sobreposição entre os

Tabela 1. Mediana, estimativa do efeito relativo de tratamento (ER) e intervalo de confiança para ER (IC) para severidade da begomovirose, e resultados de produtividade em híbridos de tomate para processamento industrial no Ensaio 1 median, estimative of treatment relative effects (ER), and confidence interval for (ER) for begomoviruse severity, and yield for processing tomato hybrids, Trial 1\}. Morrinhos, Embrapa Hortaliças/Instituto Federal Goiano, 2010.

\begin{tabular}{|c|c|c|c|c|c|}
\hline \multirow{2}{*}{ Híbridos $^{1}$} & \multirow{2}{*}{ Mediana } & \multirow{2}{*}{ ER } & \multicolumn{2}{|c|}{ IC $(95 \%)$} & \multirow{2}{*}{ Produtividade (t/ha) } \\
\hline & & & Limite inferior & Limite superior & \\
\hline AP 529 & 3 & 0,66 & 0,61 & 0,70 & 82,5 \\
\hline AP 533 & 3 & 0,66 & 0,61 & 0,70 & 91,3 \\
\hline BQ $145^{*}$ & 3 & 0,66 & 0,61 & 0,70 & 101,0 \\
\hline BQ $210^{*}$ & 2 & 0,19 & 0,15 & 0,24 & 81,7 \\
\hline BQ 211* & 3 & 0,50 & 0,24 & 0,76 & 83,6 \\
\hline Heinz 5503 & 3 & 0,50 & 0,24 & 0,76 & 75,2 \\
\hline Heinz 9553 & 3 & 0,50 & 0,24 & 0,76 & 90,1 \\
\hline Heinz 9992 & 3 & 0,50 & 0,24 & 0,76 & 82,7 \\
\hline BRS Sena & 1 & 0,03 & - & - & 106,4 \\
\hline HF $1-50 *$ & 2 & 0,19 & 0,15 & 0,24 & 99,4 \\
\hline HMX 7889 & 3 & 0,66 & 0,61 & 0,70 & 84,2 \\
\hline SVR $0453^{*}$ & 3 & 0,66 & 0,61 & 0,70 & 82,0 \\
\hline U 2006 & 3 & 0,66 & 0,61 & 0,70 & 79,3 \\
\hline U 232 & 3 & 0,66 & 0,61 & 0,70 & 91,8 \\
\hline UG 8169 & 3 & 0,50 & 0,24 & 0,76 & 87,7 \\
\hline CV (\%) & - & - & - & - & 15,5 \\
\hline
\end{tabular}

${ }^{1}$ AP 529, AP 533, SVR 0453: Seminis do Brasil; BQ 145, BQ 201, BQ 211: Eagle Flores Frutas \& Hortaliças; Heinz 5503, Heinz 9553, Heinz 9992: Heinz Seeds/Eagle Flores Frutas \& Hortaliças; BRS Sena: Embrapa/Eagle Flores Frutas \& Hortaliças; HF1-50: Embrapa; HMX 7889: Harris Moran/Agristar do Brasil; U 2006, U 232: Nunhems Brasil-Bayer Crop Science; UG 8169: United Genetics/Agristar do Brasil. *Híbridos experimentais (experimental hybrids). 
Tabela 2. Mediana, estimativa do efeito relativo de tratamento (ER) e intervalo de confiança (IC) para ER para severidade da mancha-bacteriana, e resultados de produtividade em híbridos de tomate para processamento indstrial no Ensaio 2 \{median, estimative of treatment relative effects (ER), and confidence interval for (ER) for bacterial spot severity, and yield for processing tomato hybrids, Trial 2\}. Morrinhos, Embrapa Hortaliças/Instituto Federal Goiano, 2010.

\begin{tabular}{|c|c|c|c|c|c|}
\hline \multirow[b]{2}{*}{ Híbridos $^{1}$} & \multirow[b]{2}{*}{ Mediana } & \multirow[b]{2}{*}{ ER } & \multicolumn{2}{|c|}{ IC $(95 \%)$} & \multirow{2}{*}{$\begin{array}{c}\text { Produtividade } \\
\text { (t/ha) }\end{array}$} \\
\hline & & & $\begin{array}{l}\text { Limite } \\
\text { inferior }\end{array}$ & $\begin{array}{c}\text { Limite } \\
\text { superior }\end{array}$ & \\
\hline AP 529 & 7,1 & 0,68 & 0,50 & 0,81 & $38,3 \quad a b$ \\
\hline AP 533 & 7,3 & 0,55 & 0,14 & 0,90 & $37,2 \quad a b$ \\
\hline BQ $145^{*}$ & 8,1 & 0,77 & 0,31 & 0,94 & 33,7 \\
\hline BQ 210* & 6,6 & 0,51 & 0,28 & 0,73 & $38,2 \quad a b$ \\
\hline BQ $211^{*}$ & 7,0 & 0,49 & 0,17 & 0,82 & $39,7 \quad \mathrm{ab}$ \\
\hline CVR 54* & 5,8 & 0,25 & 0,09 & 0,56 & $54,0 \quad a b$ \\
\hline Heinz 5503 & 6,7 & 0,55 & 0,34 & 0,74 & $36,2 \mathrm{ab}$ \\
\hline Heinz 9553 & 6,2 & 0,38 & 0,21 & 0,59 & $48,1 \quad a b$ \\
\hline Heinz 9992 & 6,4 & 0,45 & 0,16 & 0,78 & $43,4 \quad a b$ \\
\hline BRS Sena & 6,3 & 0,37 & 0,23 & 0,55 & 56,5 a \\
\hline HF $1-50 *$ & 5,2 & 0,08 & 0,05 & 0,21 & $48,8 \quad \mathrm{ab}$ \\
\hline HMX 7889 & 6,3 & 0,39 & 0,16 & 0,69 & $51,6 \quad a b$ \\
\hline SVR 0453* & 7,0 & 0,57 & 0,22 & 0,86 & $46,6 \quad a b$ \\
\hline U 2006 & 7,4 & 0,74 & 0,57 & 0,86 & $36,5 \quad a b$ \\
\hline U 232 & 7,9 & 0,67 & 0,18 & 0,93 & $44,0 \quad a b$ \\
\hline UG 8169 & 7,0 & 0,55 & 0,26 & 0,80 & $45,1 \quad a b$ \\
\hline $\mathrm{CV}(\%)$ & - & - & - & - & 16,6 \\
\hline
\end{tabular}

${ }^{1}$ AP 529, AP 533, SVR 0453: Seminis do Brasil; BQ 145, BQ 201, BQ 211: Eagle Flores Frutas \& Hortaliças; Heinz 5503, Heinz 9553, Heinz 9992: Heinz Seeds/Eagle Flores Frutas \& Hortaliças; BRS Sena: Embrapa/Eagle Flores Frutas \& Hortaliças; HF1-50: Embrapa; HMX 7889: Harris Moran/Agristar do Brasil; U 2006, U 232: Nunhems Brasil-Bayer Crop Science; UG 8169: United Genetics/Agristar do Brasil; ${ }^{2}$ Médias seguidas de mesma letra nas colunas não diferem entre si, teste de Tukey, $\mathrm{p}<0,05$ (means followed by the same letter in the column do not differ from each other, Tukey test, $\mathrm{p}<0.05)$; ${ }^{*}$ Híbridos experimentais (experimental hybrids).

valores de intervalo de confiança entre esses dois grupos (Shah \& Madden, 2004).

Quanto à produtividade, detectaram-se diferenças significativas entre os híbridos BRS Sena (56,5 t/ha) e BQ-145 (33,7 t/ha). A correlação de Spearman foi negativa $(\mathrm{r}=-0,51)$ e significativa $(\mathrm{p}=0,0004)$, indicando que em torno de $25 \%$ da variação da produtividade pôde ser explicada pela variação da mancha-bacteriana e confirmando o senso comum de que essa doença é um importante fator limitante da produção do tomate para processamento industrial. A produtividade foi bastante reduzida, abaixo da média nacional registrada para o decênio 2004/13, de 82,9 t/ha (Melo \& Melo, 2014). Esse fato pode estar relacionado à ocorrência intensa de chuvas no final do ciclo, favorável não cela principal) foi significativo a $7 \%$ e o subfator, híbridos (subparcela) foi significativo a $p=0,0051$. Entretanto, a interação entre os dois fatores não apresentou significância $(\mathrm{p}=0,58)$.

A incidência de plantas com infecção por begomovírus no terceiro ensaio foi inferior ao primeiro ensaio, com as medianas das notas de severidade da doença variando em torno de 2 (sintomas moderados) (Tabelas $1 \mathrm{e}$ 3), mas, ainda assim, nas parcelas não inoculadas com mancha-bacteriana foi possível observar diferenças significativas entre os híbridos $(\mathrm{p}=0,01)$. $\mathrm{O}$ maior nível de resistência foi observado no híbrido BRS Sena, que apresentou a menor mediana em ambos os ensaios em que a begomovirose foi avaliada. No terceiro ensaio, o híbrido BRS Sena se diferenciou apenas dos híbridos que tiveram a mediana superior a 2 , sem a sobreposição do IC (Tabela 3) (Shah \& Madden, 2004).

Em relação à mancha-bacteriana, as notas da primeira avaliação variaram em média de 4,9 a 7,2 e, da última, de 8,1 a 9,4 , indicando que, embora a severidade da doença tenha aumentado ao longo do tempo, houve uma menor amplitude de severidade entre os híbridos na leitura final. Os híbridos CVR 54, BRS Sena, BA 5446 e HMX 7889, com menor AACPMab, diferiram dos três híbridos que apresentaram maior AACPMab (N-901, Heinz 9992 e Heinz 9553) (Tabela 3). Os híbridos Heinz 9553 e U 2006, já relatados como superiores a outros genótipos em relação à mancha-bacteriana (Pontes et al., 2012; Nascimento et al., 2013), não confirmaram tal superioridade neste ensaio (Tabela 3). Este fato talvez esteja relacionado à interferência de begomovirose na suscetibilidade à mancha-bacteriana, pois esses híbridos comerciais não são portadores do gene $T y$-1 que confere tolerância à begomovirose. No presente trabalho foram híbridos que mostraram os maiores valores da mediana para begomovirose nos ensaios onde ela foi avaliada (Tabelas 1 e 3).

Ao se avaliar a produtividade, a interação entre os fatores inoculação e híbrido não foi significativa, o que indica que, quando os dados são tomados de forma conjunta, a inoculação com Xanthomonas sp. não afetou de forma diferenciada o comportamento produtivo dos híbridos. Os dois híbridos 
Tabela 3. Mediana, estimativa do efeito relativo de tratamento (ER) e intervalo de confiança para ER (IC) para severidade da begomovirose e Área Abaixo da Curva de Progresso da Mancha-bacteriana (AACPMab) em híbridos de tomate para processamento industrial no Ensaio 3 median, estimative of treatment relative effects (ER), and confidence interval for (ER) for begomoviruse severity, and Area Under the Bacterial Spot Progress Curve (AACPMab) on processing tomato hybrids, Trial 3$\}$. Morrinhos, Embrapa Hortaliças/Instituto Federal Goiano, 2011.

\begin{tabular}{|c|c|c|c|c|c|c|}
\hline \multirow{3}{*}{ Híbridos $^{1}$} & \multicolumn{4}{|c|}{ Begomovirose } & & \\
\hline & \multirow[b]{2}{*}{ Mediana } & \multirow[b]{2}{*}{ ER } & \multicolumn{2}{|c|}{ IC $(95 \%)$} & \multirow{2}{*}{ - AACPMab } & \\
\hline & & & $\begin{array}{c}\text { Limite } \\
\text { inferior }\end{array}$ & $\begin{array}{c}\text { Limite } \\
\text { superior }\end{array}$ & & \\
\hline Heinz 9992 & 2,0 & 0,37 & 0,12 & 0,61 & 209,71 & $\mathrm{a}$ \\
\hline N-901 & 2,0 & 0,37 & 0,12 & 0,61 & 207,10 & $\mathrm{a}$ \\
\hline Heinz 9553 & 2,0 & 0,52 & 0,07 & 0,98 & 202,19 & $\mathrm{a}$ \\
\hline E $8755^{*}$ & 2,0 & 0,50 & 0,24 & 0,76 & 197,48 & $\mathrm{ab}$ \\
\hline AP 533 & 2,7 & 0,90 & 0,83 & 0,97 & 193,02 & $\mathrm{abc}$ \\
\hline U 2006 & 2,3 & 0,71 & 0,51 & 0,90 & 192,83 & $\mathrm{abc}$ \\
\hline HMX 7889 & 2,0 & 0,37 & 0,12 & 0,61 & 174,03 & bcd \\
\hline BA $5446^{*}$ & 2,3 & 0,62 & 0,28 & 0,97 & 167,29 & $\mathrm{~cd}$ \\
\hline BRS Sena & 1,0 & 0,15 & 0,04 & 0,26 & 165,38 & d \\
\hline CVR 54* & 2,0 & 0,50 & 0,38 & 0,62 & 160,52 & d \\
\hline CV (\%) & - & - & - & - & 15,5 & \\
\hline
\end{tabular}

${ }^{1}$ AP 533: Seminis do Brasil; E 8755, BA 5446: Eagle Flores Frutas \& Hortaliças; Heinz 9553, Heinz 9992: Heinz Seeds/Eagle Flores Frutas \& Hortaliças; BRS Sena: Embrapa/Eagle Flores Frutas \& Hortaliças; HMX 7889: Harris Moran/Agristar do Brasil; U 2006, N-901: Nunhems Brasil-Bayer Crop Science; CVR 54: CVR Plant Breeding. ${ }^{2}$ Médias seguidas de mesma letra nas colunas não diferem entre si, teste de Tukey, $\mathrm{p}<0,05$ (means followed by the same letter in the column do not differ from each other, Tukey test, $\mathrm{p}<0.05)$; ${ }^{*}$ Híbridos experimentais (experimental hybrids).

Tabela 4. Produtividade média de híbridos de tomate para processamento indstrial, produtividade das parcelas não inoculadas e inoculadas com Xanthomonas spp. e significância (P) da comparação entre parcelas não inoculadas e inoculadas para cada híbrido no Ensaio 3 (average yield of processing tomato hybrids, yield in plots inoculated and non-inoculated with Xanthomonas spp. and significance of contrasts within hybrids for non-inoculated and inoculated plots, Trial 3). Morrinhos, Embrapa Hortaliças/Instituto Federal Goiano, 2011.

\begin{tabular}{lclccl}
\hline \multirow{2}{*}{ Híbridos $^{1}$} & \multirow{2}{*}{ Produtividade $^{2}$} & \multicolumn{3}{c}{ Produtividade (t/ha) } & \multirow{2}{*}{ P $>\mathbf{F}^{\mathbf{3}}$} \\
\cline { 3 - 5 } & & & Não inoculado & Inoculado & \\
\hline BA 5446* & 138,0 & a & 152,2 & 123,9 & $0,0525^{\text {NS }}$ \\
BRS Sena & 130,5 & ab & 154,0 & 107,1 & 0,0021 \\
HMX 7889 & 121,2 & abc & 143,0 & 99,4 & 0,0039 \\
E 8755* & 115,4 & abc & 140,3 & 90,4 & 0,0012 \\
N 901 & 112,0 & abc & 133,6 & 90,3 & 0,0041 \\
U 2006 & 111,6 & abc & 123,7 & 99,5 & $0,0953^{\text {NS }}$ \\
Heinz 9992 & 108,4 & abc & 131,0 & 85,8 & 0,0029 \\
CVR 54* & 106,3 & abc & 116,6 & 102,9 & $0,3938^{\text {NS }}$ \\
Heinz 9553 & 100,1 & bc & 110,3 & 89,9 & $0,1572^{\text {NS }}$ \\
AP 533 & 95,8 & c & 120,8 & 70,8 & 0,0011 \\
\hline CV (\%) & 15,1 & \multicolumn{4}{l}{} \\
\hline
\end{tabular}

${ }^{1}$ AP 533: Seminis do Brasil; E 8755, BA 5446: Eagle Flores Frutas \& Hortaliças; Heinz 9553, Heinz 9992: Heinz Seeds/Eagle Flores Frutas \& Hortaliças; BRS Sena: Embrapa/Eagle Flores Frutas \& Hortaliças; HMX 7889: Harris Moran/Agristar do Brasil; U 2006, N-901: Nunhems Brasil-Bayer Crop Science; CVR 54: CVR Plant Breeding. ${ }^{2}$ Médias seguidas de mesma letra nas colunas não diferem entre si, teste de Tukey, $p<0,05$ (means followed by the same letter in the column do not differ from each other, Tukey test, $\mathrm{p}<0.05) ;{ }^{3} \mathrm{NS}$ : não significativo (NS: non significant); *Híbridos experimentais (experimental hybrids). mais produtivos, BA 5446 e BRS Sena, diferiram do menos produtivo, AP533 (Tabela 4). Porém, quando os híbridos foram comparados individualmente, observou-se que em seis deles houve redução significativa da produtividade nas parcelas inoculadas com Xanthomonas sp. $(p \leq 0,01)$ (Tabela 4). A maior redução da produtividade entre o tratamento inoculado e não inoculado foi de 41,4 do híbrido AP533. De fato, redução de produtividade devido à mancha-bacteriana em torno de $50 \%$ foi observada em condições experimentais nos Estados Unidos e no Brasil (Pohronezny \& Volin, 1983). Com o presente trabalho, observa-se que alguns híbridos possuem potencial de, mesmo em pressão dessa doença, manter a produtividade acima da média nacional do decênio 2003/13 (Melo \& Melo, 2014).

O controle químico da mosca-branca, além das ações preconizadas na legislação vigente (Agrodefesa, 2011), é amplamente empregado na condução das lavouras de tomate para processamento, não só para mitigar a ocorrência da begomovirose, mas também o dano direto provocado pela ação do inseto, a "isoporização" dos frutos (Baldin et al., 2005). No entanto, como observado nos ensaios realizados neste trabalho, o combate à mosca-branca pela aplicação de inseticidas não garante a ausência da doença.

O híbrido BRS Sena mostrou-se tolerante à begomovirose, fato que também vem sendo observado nos testes em cultivos comerciais (Quezado-Duval, 2012) e deverá somar-se ao portfólio de cultivares disponíveis no mercado nacional. A utilização de híbridos com melhor desempenho quando da infecção pelo patógeno deverá somar-se às ferramentas de controle dessa doença.

A maior oferta de cultivares para a cadeia produtiva brasileira de tomate para processamento, com melhor desempenho agronômico em condições de pressão dessas duas doenças é desejável, uma vez que plantios são também realizados no período chuvoso, a fim de suprir a demanda de matéria-prima das empresas processadoras.

\section{AGRADECIMENTOS}

Às empresas distribuidoras de sementes Eagle Flores, Frutas \& Horta- 
liças, CVR Plant Breeding Ltda. e aos viveiros Mudas Brambilla e Vivati. À Coordenação de Apoio ao Pessoal do Ensino Superior (CAPES) pelo suporte financeiro e concessão de bolsa de Pós-Doutorado (programa Finep-PNPD-CAPES). Ao Conselho Nacional de Pesquisa (CNPq) pela concessão de bolsas de iniciação científica.

\section{REFERÊNCIAS}

AGRODEFESA. Instrução normativa $N^{\circ}$ 06/2011. 2011. Goiânia: Agência Goiana de Defesa Agropecuária. 6p.

ALBUQUERQUE LC; MARTIN DP; AVILAAC; INOUE-NAGATAAK. 2010. Characterization of tomato yellow vein streak virus, a begomovirus from Brazil. Virus Genes 40: 140-147.

ALVES SMF; NASCIMENTOAR; RODRIGUES PHF. 2006. Levantamento sistemático das micro-regiões produtoras de tomate em Goiás. In: SEMINÁRIO DE INICIAÇÃO CIENTÍfICA, 4. Anais... Anápolis: UEG. p.128-134.

ARAGÃO FAS; GIORDANO LB; MELO PCT; BOITEUX LS. 2004. Desempenho de híbridos experimentais de tomateiro para processamento industrial nas condições edafoclimáticas do cerrado brasileiro. Horticultura Brasileira 22: 529-533.

ARAÚJO ER; PEREIRARC; FERREIRAMASV; CAFÉ-FILHO AC; MOITAAW; QUEZADODUVAL AM. 2011. Effect of temperature on pathogenicity components of tomato bacterial spot and competition between Xanthomonas perforans and X. gardneri. Acta Horticulturae 914: 39-42.

BALDIN ELL; VENDRAMIM JD; LOURENÇÃO AL. 2005. Resistência de genótipos de tomateiro à mosca-branca Bemisia tabaci (Gennadius) biótipo B (Hemiptera: Aleyrodidae). Neotropical Entomology 34: 435-441.

BARRETO SS; HALLWASS M; AQUINO OM; INOUE-NAGATAAK. 2013. A study of weeds as potential inoculum sources for a tomatoinfecting begomovirus in central Brazil. Phytopathology 103: 436-444.

BOITEUX LS; FONSECA MEN.; GIORDANO LB; MELO PCT. 2012. Melhoramento genético. In: CLEMENTE FMVT; BOITEUX LS (eds). Produção de tomate para processamento industrial. Brasília: Embrapa. p.31-50.

BRUNNER E; DOMHOF S; LANGER F. 2002. Nonparametric Analysis of Longitudinal Data in Factorial Experiments. New York: John Wiley \& Sons. 261p.

CAMARGO AMMP; CAMARGO FP; ALVES HS; CAMARGO FILHO WP. 2006a. Desenvolvimento do sistema agroindustrial do tomate. Informações Econômicas 36: 53-58.

CAMARGO FP; ALVES HS; CAMARGO FILHO WP; VILELA NJ. 2006b. Cadeia produtiva de tomate industrial no Brasil: resenha da década de 1990, produção regional e perspectivas. Informações Econômicas 36: 7-20.

CASTILLO-URQUIZA GP; BEZERRA JUNIOR
JEA; BRUCKNER FP; LIMA ATM.; VARSANI AC; ALFENAS-ZERBINI P; ZERBINI FM. 2008. Six novel begomoviruses infecting tomato and associated weeds in Southeastern Brazil. Archives of Virology 153: 1985-1989.

COMISSÃO DE FERTILIDADE DE SOLOS DE GOIÁS. 1988. Recomendações de corretivos e fertilizantes para Goiás. $5^{a}$ aproximação. Goiânia: UFG/Emgopa. 10p. (Informativo Técnico, 1).

COSTA RA; SANTOS FO. 2010. Expansão agrícola e vulnerabilidade natural do meio físico no sul goiano. GeoAtos 10: 23-35.

DILLARD HR; JOHNSTON SA; COBB AC; HAMILTON GH. 1997. An assessment of fungicide benefits for the control of fungal diseases of processing tomatoes in New York and New Jersey. Plant Disease 81: 677-681.

FERNANDES FR; ALBUQUERQUE LC; GIORDANO LB; BOITEUX LS; ÁVILAAC; INOUE-NAGATA AK. 2008. Diversity and prevalence of Brazilian bipartite begomovírus species associated to tomatoes. Virus Genes 36: 251-258.

GIORDANO LB; FONSECA MEN; SILVA JBC; INOUE-NAGATA AK; BOITEUX LS. 2005. Efeito da infecção precoce por Begomovirus com genoma bipartido em características de frutos de tomate industrial. Horticultura Brasileira 23: 815-818.

JONES JB; BOUZAR H; STALL RE; SCHAAD NW. 2004. Reclassification of the xanthomonads associated with bacterial spot disease of tomato and pepper. Systematic Applied Microbiology 27: 755-762.

JONES JB; LACY GH; BOUZAR H; MINSAVAGE GV; STALL RE; SCHAAD NW. 2005. Bacterial spot. Worldwide distribution, importance and review. Acta Horticulturae 695: 27-33.

MELO PCR; MELO AMT. 2014. Desafios da cadeia de tomate. Campo \& Negócios, Anuário HF 2014, p.7-13.

MELO PCT; VILELA NJ. 2004. Desempenho da cadeia agroindustrial brasileira do tomate na década de 90. Horticultura Brasileira 22: 154-160.

MELO PCT; VILELA NJ. 2005. Desafios e perspectivas para a cadeia brasileira do tomate para processamento industrial. Horticultura Brasileira 23: 154-157.

NASCIMENTOAR; FERNANDES PM; BORGES LC; MOITA AW; QUEZADO-DUVAL AM. 2013. Controle químico da mancha-bacteriana do tomate para processamento industrial em campo. Horticultura Brasileira 31: 15-24.

OBRADOVIC AO; MAVRIDIS A; RUDOLPH $\mathrm{K}$; JANSE J; ARSENIJEVIC M; JONES JB; MINSAVAGE GV; WANG JF. 2004. Characterization and PCR-based typing of Xanthomonas campestris pv. vesicatoria of pepper and tomato pathogen in Serbia. European Journal of Plant Pathology 110: 285-291.

POHRONEZNY K; VOLIN RB. 1983. The effect of bacterial spot on yield and quality of fresh market tomatoes. HortScience 18: 69-70.

PONTES NC; MOITAAW; QUEZADO-DUVAL AM. 2012. Estabilidade da resistência de 'Ohio 8245 ' e 'Heinz 9553' à mancha bacteriana do tomateiro. Horticultura Brasileira 30: 99-105. QUEZADO-DUVAL AM. 2012. Nova Opção.
Cultivar HF 11: 05-07.

QUEZADO-DUVAL AM; LEITE RP; TRUFFI D; CAMARGO LEA. 2004. Outbreaks of bacterial spot caused by Xanthomonas gardneri on processing tomato in Central-West Brazil. Plant Disease 88:157-161.

QUEZADO-DUVAL AM; LOPES CA; LEITE JÚNIOR RP; LIMA MF; CAMARGO LEA. 2005. Diversity of Xanthomonas spp. associated with bacterial spot of processing tomatoes in Brazil. Acta Horticulturae 695: 101-108.

QUEZADO-DUVAL AM; PONTES NC; NASCIMENTO AR; MOITA AW. 2011. Metodologia de avaliação da severidade da mancha bacteriana em tomateiro para processamento industrial. Brasília: Embrapa. 24p. (Boletim de Pesquisa e Desenvolvimento 73).

ROBBINS MD; DARRIGUES A; SIM SC; MASUD MAT; FRANCIS DM. 2009. Characterization of hypersensitive resistance to bacterial spot race T3 (Xanthomonas perforans) from tomato accession PI 128216. Phytopathology 99: 1037-1044.

ROJAS MR; GILBERTSON RL; RUSSELL DR; MAXWELL DP. 1993. Use of degenerate primers in the polymerase chain reaction to detect whitefly-transmitted geminiviruses. Plant Disease 77: 340-347.

SCOTT JW; JONES JB; SOMODI GC. 1995. Screening tomato accessios for resistance to Xanthomonas campestris pv. vesicatoria, race T3. HortScience 30: 579-581.

SHAH DA; MADDEN LV. 2004. Nonparametric analysis of ordinal data in designed factorial experiments. Phytopathology 94: 33-43.

STALL RE; JONES JB; MINSAVAGE GV. 2009. Durability of resistance in tomato and pepper to xanthomonads causing bacterial spot. Annual Review of Phytopathology 47: 265-284.

VILELA NJ; MELO PCT; BOITEUX LS; CLEMENTE FMVT. 2012. Perfil socioeconômico da cadeia agroindustrial no Brasil. In: CLEMENTE FMVT; BOITEUX LS (eds). Produção de tomate para processamento industrial. Brasília: Embrapa. p.17-27.

VILLAS BÔAS GL; CASTELO BRANCO M. 2009. Manejo integrado da mosca-branca (Bemisia tabaci) em Sistema de produção Integrada de tomate indústria (PITI). Brasília: Embrapa Hortaliças. 15p. (Circular Técnica, 70).

VILLAS BÔAS GL; MELO PE; CASTELO BRANCO M; GIORDANO LB; MELO FF. 2007. Desenvolvimento de um modelo de produção integrada de tomate indústria - PITI. In: ZAMBOLIM L; LOPES CA; PICANÇO $\mathrm{MC}$; COSTA H (eds). Manejo Integrado de Doenças e Pragas - Hortaliças. Viçosa: UFV/ CNPH. p.349-362.

WANG JF.; JONES JB; SCOTT JW; STALL RE. 1994. Several genes in Lycopersicon esculentum control hypersensitivity to Xanthomonas campestris pv. vesicatoria. Phytopathology 84: 702-706.

YANG W; MILLER SA; SCOTT JW; JONES JB; FRANCIS DM. 2005. Mining tomato genome sequence databases for molecular markers: Application to bacterial resistance and marker assisted selection. Acta Horticulturae 695: 241-250. 